The Korean Economic Review

Volume 29, Number 1, Summer 2013, 211-233.

\title{
Determinants of Labor Market Outcomes of Disabled Men Before and After the Americans with Disabilities Act of 1990*
}

\author{
Chung Choe**
}

\begin{abstract}
This study compares the labor market experiences of men with disabilities before and after the implementation of the Americans with Disabilities Act of 1990. After estimating employment and wage functions using the Heckman sample selection model, we decompose the employment and wage differentials using appropriate decomposition techniques (Even and McPherson 1990; Neuman and Oaxaca 2004). The analyses are performed using data from the Survey of Income Program Participation extending from six years before to 11 years after the passage of the ADA. The results indicate that employment and wage gaps between disabled and nondisabled men have risen sharply over time. Overall, discrimination on entry to employment is more important than wage discrimination and the ADA had less effect on reducing discrimination in employment opportunities than on wage discrimination.
\end{abstract}

JEL Classification: I12, J58, J71, K31

Keywords: Labor Market Discrimination, Disabilities, Americans with Disabilities Act

\section{Introduction}

On July 26, 1990, the Americans with Disabilities Act (ADA hereafter) became law and extended civil rights protections to persons with disabilities. The antidiscrimination law was enacted to ensure the equality of opportunity for persons with disabilities, promote their economic self-sufficiency, and encourage independent living. The ADA was expected to increase the employment rates and

Received: Dec. 11, 2012. Revised: April 4, 2013. Accepted: May 27, 2013.

* This paper is the third chapter of my Ph.D. dissertation at the University of Arizona. I am deeply indebted to my thesis advisors, Price Fishback and Ronald Oaxaca, for their guidance and support. Detailed comments and suggestions by the two referees and Marjorie Baldwin are gratefully acknowledged. I am also grateful to Alfonso Flores-Lagunes, Keisuke Hirano and seminar participants at The University of Arizona and IRISS 10th Anniversary Workshop for their helpful comments. Thanks also to David Brightwell for his editorial assistance. All errors are mine.

** CEPS/INSTEAD and Katholieke Universiteit Leuven, L-4364, Esche-sur-Alzette, Luxembourg. Phone: (352) 585855 402. Fax: (352) 585 560. E-mail: chung.choe@ceps.lu 
wages of people with disabilities, but researchers find the Act had little impact on their labor market outcomes, or even a slight negative effect on employment opportunities.

Descriptive data from the Survey of Income and Program Participation (SIPP hereafter) show that following implementation of the ADA the relative socioeconomic status of persons with disabilities has worsened in terms of earnings and employment (Tables 1 and 2). In particular, the difference in employment rates between nondisabled persons and persons with disabilities have significantly increased, while wage differentials between the two groups remain constant. These data, however, do not take account of differences in the productivity-related characteristics of disabled and nondisabled workers. The goal of this research is to identify what part of the relative decline in relative employment and wages for persons with disabilities can be explained by changes in measurable factors and what part remains unexplained (attributed to discrimination and residual effects).

Several empirical studies (DeLeire 2000, 2001; Acemoglu and Angrist 2001; Beegle and Stock 2003) investigate how the ADA has affected labor market outcomes for persons with disabilities. With respect to employment opportunities, DeLeire (2000) and Acemoglu and Angrist (2001) find the ADA contributed to an increase in the unemployment rate among people with disabilities. In contrast, Beegle and Stock (2003) examining various state-level antidiscrimination laws passed prior to the ADA find the laws are associated with lower relative earnings and slightly lower labor force participation rates among persons with disabilities, but not with lower relative employment rates. In terms of wage differentials, Schumacher and Baldwin (2000) find an increase in wage differentials between workers with and without disabilities over the period the ADA was implemented (1990 to 1993). Moon and Shin (2006), however, show that the estimated effects of the ADA on the dollar-valued measures of well-being (i.e., wages and total personal income) for men with disabilities are sensitive to how disability is defined. They report larger and more significant effects of the ADA effects for objective measures of disability than for self-reported measures.

A fundamental assumption underlying the $\mathrm{ADA}$ is that persons with disabilities have low economic status in part because of labor market discrimination and lack of access to employment opportunities. While many researchers (Johnson and Lambrinos 1985, Baldwin and Johnson 1994, 2000) examine the potential impact of discrimination on the labor market experience of persons with disabilities, few studies attempt to evaluate the impact of the ADA from a discrimination perspective. A noteworthy exception is DeLeire (2001), who finds the discriminatory component of the wage gap does not decrease after introduction of the ADA (between 1984 and 1993), but the author does not consider the impact of the ADA on discrimination in employment.

There are several contributions of this study. First, we investigate the changes in 
explained and unexplained (discrimination and residual effects) differentials between persons with and without disabilities pre- and post-ADA, in terms of both employment and wage rates. Second, we apply an enhanced decomposition methodology suggested by Neuman and Oaxaca (2004), that can be applied to sample selection-corrected wage equations to present the results in terms of actual wage differentials, as opposed to offer wage differentials. Third, we use information from four panels of SIPP $(1984,1990,1996,2001)$ so that comparisons cover a longer time span before and after the passage of the ADA than has been studied

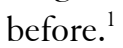

Consistent with previous work, we find no improvement in either employment rates or wages for persons with disabilities after introduction of the antidiscrimination law. The decomposition analyses, however, reveal interesting findings, which have not been reported in previous studies. For instance, we find no significant changes in the unexplained component of the wage differential in the years following the passage of the law, whereas the unexplained differential had been increasing in years prior to the passage of the ADA. On the other hand, in the decomposition results for the employment differential, both the explained and unexplained components increase in absolute terms after the enactment of the ADA, although in relative terms the discrimination portion remains constant over the post-ADA period.

\section{Econometric Methods}

This study focuses on explaining how observed and unobserved factors affect differentials in employment opportunities and wages between persons with and without disabilities. To decompose the wage differentials, we estimate wage functions with the Heckman sample selection correction, which accounts for nonrandom selection into employment. An enhanced decomposition method (Neuman and Oaxaca, 2004), which includes a decomposition of the difference in selectivity correction terms, is applied to separate the total wage gap into explained and unexplained components. ${ }^{2}$ Using coefficient estimates from the first stage employment models used to estimate the Heckman models, and means for the full samples of employed and not employed persons, we also decompose the differentials of employment rates, using a decomposition technique applicable to

\footnotetext{
${ }^{1}$ Previous studies allowed insufficient time periods for evaluation of the ADA. For example, DeLeire (2001) utilized data from SIPP 1984 and 1993 to evaluate the impact of the ADA on changes in wage discrimination against people with disabilities.

${ }^{2}$ In the discrimination literature, people normally call the unexplained part of the wage or employment differential 'discrimination.' This is the part which is not explained by the difference of observed characteristics of the two between groups.
} 
models with binary dependent variables (Even and McPherson 1990).

\section{Estimating Employment Participation and Wage}

Following the Heckman two-step procedure, we first estimate employment equations separately for disabled $(D)$ and nondisabled $(N D)$ individuals. The employment models are the basis for an Oaxaca-type (1973) decomposition of the disability-related employment gap and for constructing the selectivity correction terms included in the wage equations. Using the probit models, we estimate the employment equations as follows:

$$
\operatorname{Pr}\left(E_{i}=1\right)=\Phi\left(\gamma_{j 0}+\gamma_{j 1} X_{i}^{-}+\gamma_{j 2} Z_{i}\right)
$$

where $\Phi$ is the normal cumulative density function; $E_{i}$ is an indicator variable of employment status for the $i^{\text {th }}$ worker; $\gamma_{j 0}$ is a constant term $(j=N D, D)$; $X_{i}^{-}$is a subset of variables included in the wage equation; ${ }^{3}$ and $Z_{i}$ is a vector of variables that satisfy exclusion restrictions. We use non-labor income and controls for family structure as determinants of the employment decision but exclude these variables from the wage equation.

Probit estimates of the employment decision are used to construct the selectivity variable (inverse Mills ratio) as follows:

$$
\lambda_{i}=\frac{\phi\left(\hat{\gamma}_{j 0}+\hat{\gamma}_{j 1} X_{i}^{-}+\hat{\gamma}_{j 2} Z_{i}\right)}{\Phi\left(\hat{\gamma}_{j 0}+\hat{\gamma}_{j 1} X_{i}^{-}+\hat{\gamma}_{j 2} Z_{i}\right)}
$$

where $\phi$ is the normal density function. We include the lambda term in the wage equations to resolve sample selection issues (i.e. offer wages are not observed for non-workers) so that coefficient estimates from ordinary least squares are unbiased.

We specify the wage functions as follows:

$$
W_{i}=\alpha_{j}+\beta_{j} X_{i}+\theta_{j} \lambda_{i}+\varepsilon_{i}
$$

where $W_{i}$ is the log wage of the $i^{t h}$ worker; $\alpha_{j}$ is a constant term $(j=N D, D) ; X_{i}$ is a vector of variables controlling for human capital, job-related, and socio-demographic characteristics, with associated coefficient vector $\beta_{j} ; \lambda_{i}$ is the selectivity correction term, with coefficient $\theta_{j}$, and $\epsilon_{i}$ is an error term with standard normal distribution.

\footnotetext{
${ }^{3}$ Theoretically, the all variables in the wage equations are expected to be included in the employment (selection) equations in the Heckman sample selection model, but we do not observe occupation and industry variables for unemployed individuals.
} 


\section{Decomposing Employment and Wage Differentials}

Results from the first step employment function are used to measure the extent to which unobserved factors influence the difference in employment rates between workers with and without disabilities. Because the dependent variable in the employment models is binary, we decompose the differentials in employment rates using a decomposition technique applicable to nonlinear models (Even and McPherson 1990).

Details of the decomposition applied to the probit models are as follows. Define nondisabled (disabled) characteristics as $H_{N D}\left(H_{D}\right)$, coefficient estimates from the probit employment functions as $\hat{\gamma}_{N D}\left(\hat{\gamma}_{D}\right)$, and sample sizes as $N_{N D}\left(N_{D}\right)$. Then the part of the employment differential explained by differences between measured characteristics of disabled and nondisabled persons is:

$$
E X P=\frac{1}{N_{N D}} \sum_{i=1}^{N_{N D}} \Phi\left(H_{i N D} \hat{\gamma}_{N D}\right)-\frac{1}{N_{D}} \sum_{i=1}^{N_{D}} \Phi\left(H_{i D} \hat{\gamma}_{N D}\right) .
$$

The corresponding measure of the unexplained component of the employment differential is:

$$
U N E X P=\frac{1}{N_{D}} \sum_{i=1}^{N_{D}} \Phi\left(H_{i N D} \hat{\gamma}_{N D}\right)-\frac{1}{N_{D}} \sum_{i=1}^{N_{D}} \Phi\left(H_{i D} \hat{\gamma}_{N D}\right)
$$

The approach closely follows the basic ideas of the traditional wage decomposition technique (Oaxaca 1973). Accordingly, given the possibility of omitted variables (especially the extent and severity of disability and its impact on the capacity to work), the usual caveat applies in interpreting the unexplained component. That is, the unexplained residual combines the extent to which persons with disabilities experience employment discrimination as well as the effect of unmeasured factors that influence the decision to work.

Once we have estimated selectivity correction terms in the wage models, it becomes an issue how to include the difference in selection effects in the wage decomposition. Neuman and Oaxaca (2004) suggest the following decomposition method under specific assumptions: ${ }^{4}$

\footnotetext{
${ }^{4}$ In Neuman and Oaxaca (2004), several methods are suggested to deal with the selection bias correction term. Among the alternatives, we selected the one that takes the most encompassing way to view discrimination. This method regards both differences in estimated $\gamma$ parameters from the probit employment equation and differences in the estimated coefficient $(\theta)$ of the selectivity variable as manifestations of discrimination. Differences in means of variables in the employment function $(H)$ are treated as nondiscriminatory endowment effects. The first assumption has been claimed by several previous researchers (see Baldwin and Johnson, 1992, 1994, and 2000 for the details), and the second is also normally assumed in the discrimination literature.
} 


$$
\begin{aligned}
\bar{W}_{N D}-\bar{W}_{D} & =\underbrace{\hat{\beta}_{N D}\left(\bar{X}_{N D}-X_{D}\right)+\hat{\theta}_{N D}\left(\hat{\lambda}_{N D}-\hat{\lambda}_{D}^{o}\right)}_{\text {Endowment }} \\
& +\underbrace{\left(\hat{\alpha}_{N D}-\hat{\alpha}_{D}\right)+\bar{X}_{D}\left(\hat{\beta}_{N D}-\hat{\beta}_{D}\right)+\hat{\theta}_{N D} \hat{\lambda}_{D}^{o}-\hat{\theta}_{D} \hat{\lambda}_{D}}_{\text {Unexplained }}
\end{aligned}
$$

where $\bar{W}_{j}$ is mean wage for group $j ; \bar{X}_{j}$ is a vector of mean characteristics for group $j$; and $\hat{\lambda}_{D}^{o}=\frac{1}{N_{D}} \sum_{i=1}^{N_{D}} \hat{\lambda}_{i D}^{o}$ and $\hat{\lambda}_{i D}^{o}=\phi\left(\hat{\gamma}_{D} H_{i N D}\right) / \Phi\left(\hat{\gamma}_{D} H_{i N D}\right) .^{5}$

Equation (5) states that the observed wage differential is the sum of: an endowment effect, attributed to differences between disabled and nondisabled workers in the mean characteristics that determine wages and employment; and an unexplained effect, attributed to differences in estimated coefficients of the wage and employment function (discrimination) and differences in the residual terms. The terms $\hat{\theta}_{N D}\left(\hat{\lambda}_{N D}-\hat{\lambda}_{D}^{o}\right)$ and $\left(\hat{\theta}_{N D} \hat{\lambda}_{D}^{o}-\hat{\theta}_{D} \hat{\lambda}_{D}\right)$ in the first and second brackets respectively are the key parts that allow us to decompose observed wages (rather than offer wages) when the selectivity correction term is included in the wage equations. ${ }^{6}$

\section{Data}

Four panels of the Survey of Income and Program Participation (SIPP 1984, 1990, 1996, 2001) are used in this study to examine how labor market discrimination against people with disabilities changed between 1984-2001. The core questionnaire of the SIPP provides detailed information on respondents' income sources, demographic characteristics, and participation in various cash and non-cash benefit programs for each month (of a four-month reference period, or Wave). A topical module administered as a supplement to the core file collects different types of information in each Wave. We merge the topical modules that include information on disabilities (functional limitations) with the corresponding core files for each year. The notable advantage of SIPP other national survey data is that it includes detailed information on health-related characteristics as well as labor market outcomes and socioeconomic status.

\footnotetext{
${ }^{5}$ See Neuman and Oaxaca (2004) for a derivation of equation (5) and alternative decomposition methods.

${ }^{6}$ When the selectivity correction term is not handled appropriately, the estimation of wage discrimination could be biased. Most previous studies (Baldwin and Johnson, 1992, 1994 and 2000; Kidd et al., 2000; Jones et al., 2006) resolve the problem by decomposing sample selection bias adjusted wage differentials (offer wage differentials) in lieu of the actual wage differentials. DeLeire (2001) applies a Tobit model to estimate the wage equations to avoid encountering the problem of the inverse Mills ratio but it is well known that results from the Tobit model are biased.
} 
Considering the timing of the passage of the ADA (1990) and the timing of the collection of SIPP surveys, we can definitely use SIPP 1984 to reflect the labor market prior to the ADA, and both SIPP 1996 and SIPP 2001 to examine changes in the labor market over the post-ADA period. However, we must be careful in interpreting results from the 1990 Panel. The Americans with Disabilities Act (ADA) was signed into law in 1990 but did not take effect until 1992 for covered employers with 25 or more employees, and until 1994 for employers with 15 or more employees. The concern is that the labor market might have changed in 1990 in anticipation of the ADA even before the law was legally effective. Because it is difficult to determine the extent of change in advance of the Act it is preferable to say that SIPP 1990 reflects a market in the process of adapting to the new law.

Disability is defined by the ADA as "...a physical or mental impairment that substantially limits a major life activity." Because this study investigates trends in the relative labor market performance of individuals with disabilities before and after the ADA, it is crucial to define the study groups as closely as possible to the ADA definition. Therefore, we define persons with disabilities as those who respond yes to the question "Do you have a physical, mental, or health condition that limits the kind and amount of work you can do?". Persons without disabilities are those who respond no to the work limitation question.

We restrict the sample to men between the ages of 18 and 62 who are not enrolled in school. The restrictions avoid complications of gender discrimination and limit the sample to individuals of working age. The SIPP contains different sample units across years, so the total number of observations varies across Panels.

We define employed persons as those who report a positive wage for the reference month (Table 1). The hourly wage variable for Equation (5) is calculated by dividing on the usual weekly wage by usual hours worked (Table 2). We exclude workers whose calculated hourly earnings are outliers: less than $\$ 3$ or more than $\$ 300$ dollars. All wage variables are expressed in terms of 2013 prices.

As explained in the previous section, we need exclusion restrictions to correct for the selection bias in wage equations. Unearned income and various family structure variables are included in the employment equation but excluded from the wage equation. These variables are expected to influence a worker's reservation wage, but not an employer's offer wage. Finally, binary variables for occupation, industry, union membership and part-time work status are included in wage equations, but cannot be included in the employment equations because such information is unavailable for those who are not employed. ${ }^{7}$

\footnotetext{
${ }^{7}$ Previous authors have used exogenous income (Kidd et al. 2000) and nonwage income and three marital status dummies (Baldwin and Johnson 2000) for exclusion restrictions.
} 


\section{Estimation Results}

\section{Descriptive Statistics}

Tables 1 and 2 provide summary statistics for all variables in the employment and wage equations. As shown in Table 1 , according to the definition of disability in this article, the proportion of the sample reporting a disability remained roughly constant between 1984-2001, starting around 10.9 percent in 1984 and increasing to slightly more than 11 percent in other years (Fig. 1).

[Figure 1] Disability Rates in the U.S. $1984-2001$

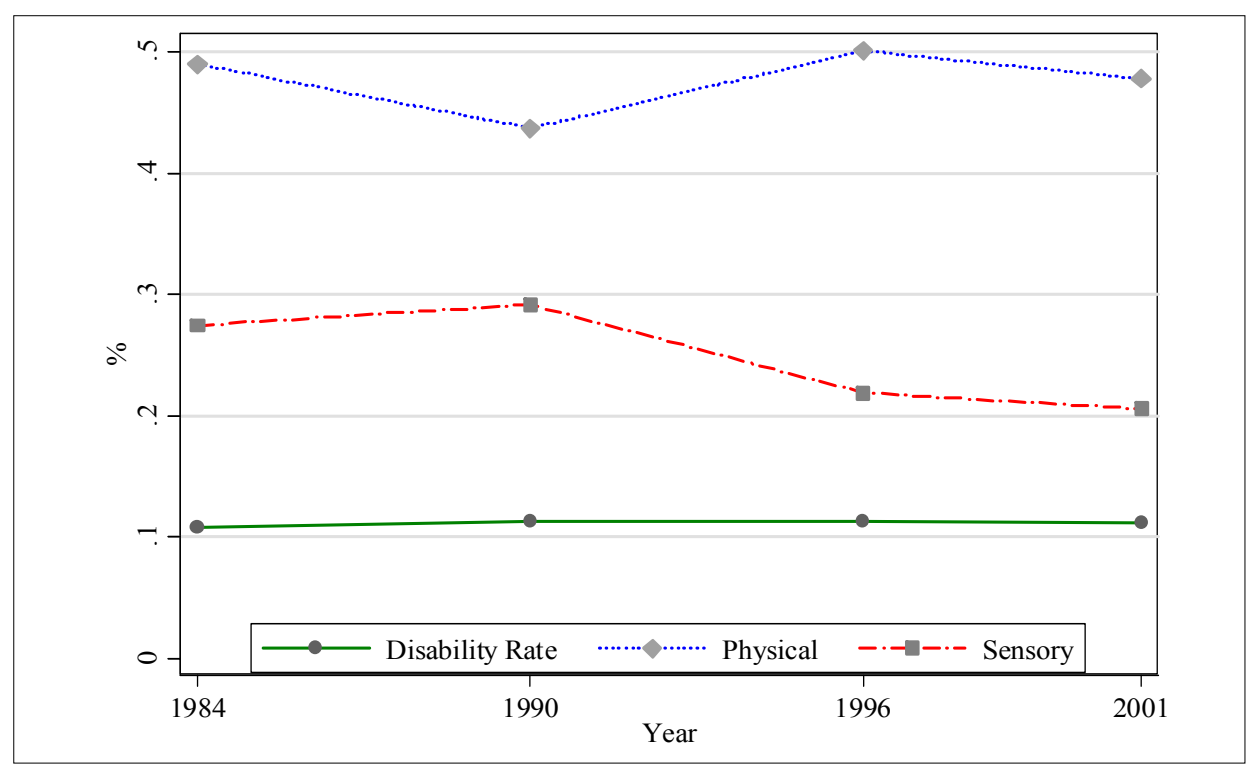

Employment rates for nondisabled men increased from 77 percent in 1984 to 87 percent in 1996, then declined to 84 percent by 2001 (Table 1). For men with disabilities, employment rates consistently decreased over the observation period: from 45 percent in 1984 to 27 percent in 2001. As a result, differences in employment rates between nondisabled and disabled men increased from 32 percentage points to 57 percentage points over the study period. This is an indication of a possible negative effect of the ADA that has also been noted in other studies (DeLeire, 2000 and Acemoglu and Angrist, 2001).

In 1984 the hourly earnings of men with disabilities was 88.3 percent of the wage for nondisabled men ( $\$ 20.92$ vs. $\$ 23.70$ ) (Table 2). The relative hourly pay for disabled men then decreased to 82 percent in 1990 (\$19.24 vs. \$23.46) and 80 percent in 1996 ( $\$ 20.94$ vs. \$26.16), before increasing to 85.1 percent in 2001 (\$23.52 vs. \$27.64) (Table 2). The raw data seems to suggest that the relative position of men with disabilities has worsened in terms of both wages and employment 


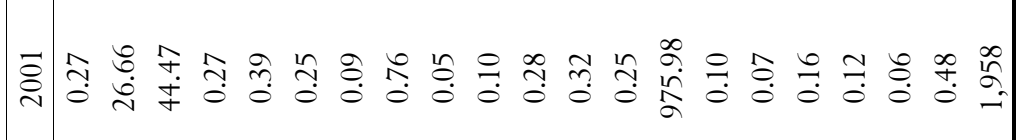

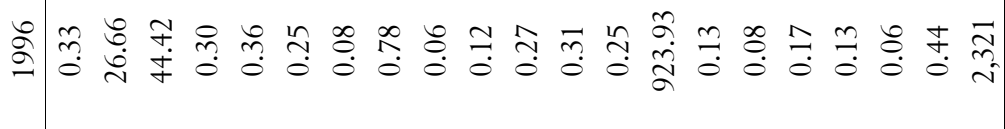

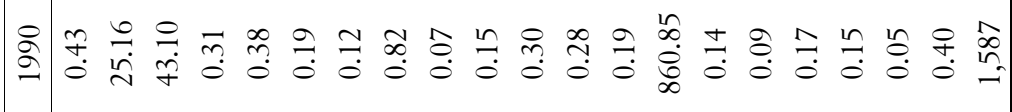

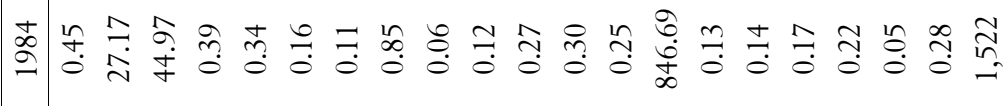

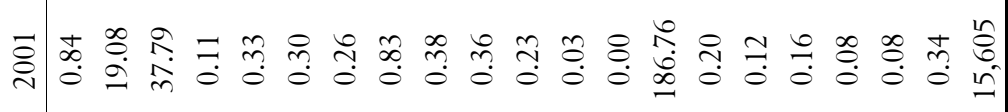

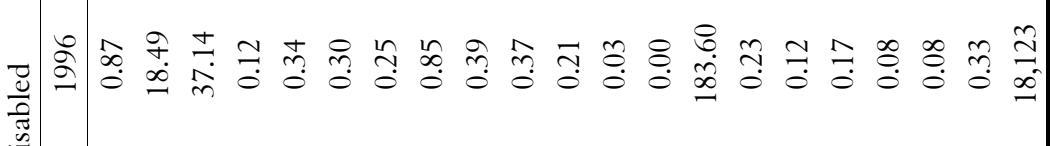

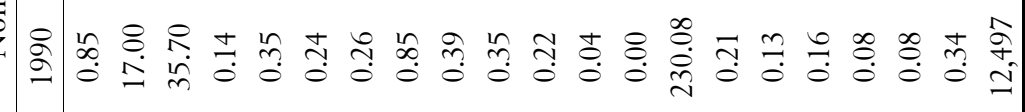

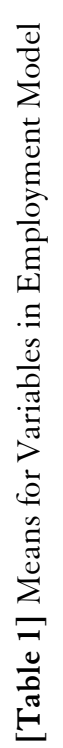

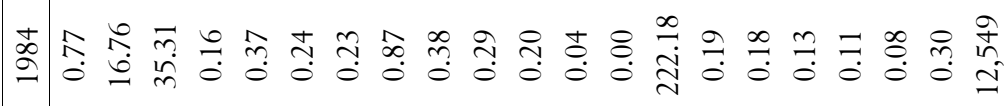

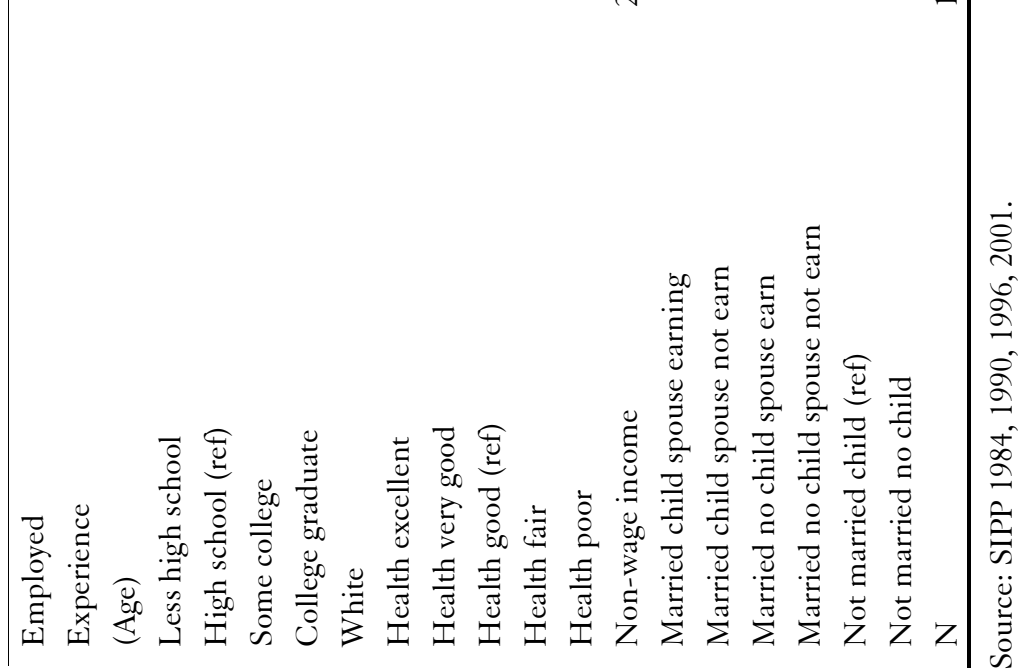


opportunities since the introduction of the ADA. The raw data do not, however, control for changes in the relative characteristics of the disabled and nondisabled groups over time, so it is necessary to implement more sophisticated analyses, controlling for differences in individual characteristics between disabled and nondisabled men to estimate the true impact of the ADA.

[Table 2] Means for Variables in Wage Model

\begin{tabular}{|c|c|c|c|c|c|c|c|c|}
\hline & \multicolumn{4}{|c|}{ Nondisabled } & \multicolumn{4}{|c|}{ Disabled } \\
\hline & 1984 & 1990 & 1996 & 2001 & 1984 & 1990 & 1996 & 2001 \\
\hline Hourly wage rate & 23.70 & 23.46 & 26.16 & 27.64 & 20.92 & 19.24 & 20.94 & 23.52 \\
\hline Experience & 16.91 & 17.44 & 18.84 & 19.50 & 24.38 & 21.72 & 23.53 & 24.28 \\
\hline Less high school & 0.15 & 0.13 & 0.11 & 0.10 & 0.28 & 0.18 & 0.15 & 0.17 \\
\hline High school (ref) & 0.37 & 0.36 & 0.34 & 0.32 & 0.37 & 0.40 & 0.39 & 0.35 \\
\hline Some college & 0.24 & 0.24 & 0.30 & 0.30 & 0.20 & 0.25 & 0.32 & 0.33 \\
\hline College graduate & 0.24 & 0.28 & 0.26 & 0.27 & 0.15 & 0.17 & 0.13 & 0.16 \\
\hline Union & 0.24 & 0.20 & 0.16 & 0.15 & 0.28 & 0.19 & 0.14 & 0.18 \\
\hline White & 0.89 & 0.86 & 0.86 & 0.85 & 0.91 & 0.89 & 0.85 & 0.82 \\
\hline Part-time & 0.05 & 0.07 & 0.19 & 0.19 & 0.09 & 0.13 & 0.39 & 0.39 \\
\hline Professional & 0.23 & 0.25 & 0.26 & 0.28 & 0.17 & 0.20 & 0.17 & 0.20 \\
\hline Clerical & 0.20 & 0.20 & 0.20 & 0.20 & 0.18 & 0.19 & 0.22 & 0.21 \\
\hline Service (ref) & 0.10 & 0.10 & 0.10 & 0.11 & 0.13 & 0.14 & 0.14 & 0.18 \\
\hline Skilled & 0.21 & 0.19 & 0.19 & 0.18 & 0.22 & 0.16 & 0.17 & 0.15 \\
\hline Semi-skilled & 0.17 & 0.16 & 0.16 & 0.14 & 0.20 & 0.20 & 0.17 & 0.16 \\
\hline Labored & 0.09 & 0.09 & 0.09 & 0.09 & 0.10 & 0.11 & 0.12 & 0.10 \\
\hline Farm (ref) & 0.02 & 0.02 & 0.02 & 0.02 & 0.03 & 0.03 & 0.02 & 0.02 \\
\hline Mining & 0.01 & 0.01 & 0.01 & 0.01 & 0.02 & 0.01 & 0.01 & 0.01 \\
\hline Construction & 0.09 & 0.09 & 0.09 & 0.10 & 0.06 & 0.07 & 0.07 & 0.09 \\
\hline Manufacture & 0.29 & 0.25 & 0.24 & 0.20 & 0.34 & 0.25 & 0.20 & 0.18 \\
\hline Wholesale trade & 0.06 & 0.06 & 0.06 & 0.05 & 0.05 & 0.05 & 0.06 & 0.03 \\
\hline Retail trade & 0.14 & 0.14 & 0.14 & 0.15 & 0.14 & 0.17 & 0.16 & 0.19 \\
\hline Finance, insurance, \& real estate & 0.04 & 0.05 & 0.04 & 0.05 & 0.03 & 0.04 & 0.03 & 0.04 \\
\hline Public utility & 0.04 & 0.04 & 0.04 & 0.03 & 0.05 & 0.03 & 0.03 & 0.03 \\
\hline Transportation & 0.06 & 0.07 & 0.06 & 0.06 & 0.05 & 0.06 & 0.08 & 0.07 \\
\hline Services & 0.18 & 0.21 & 0.23 & 0.26 & 0.17 & 0.23 & 0.26 & 0.28 \\
\hline Public administration & 0.06 & 0.06 & 0.07 & 0.07 & 0.07 & 0.06 & 0.06 & 0.07 \\
\hline Health excellent & 0.42 & 0.39 & 0.38 & 0.38 & 0.09 & 0.11 & 0.09 & 0.09 \\
\hline Health very good & 0.32 & 0.36 & 0.38 & 0.36 & 0.19 & 0.24 & 0.21 & 0.20 \\
\hline Health good (ref) & 0.21 & 0.22 & 0.21 & 0.22 & 0.36 & 0.36 & 0.37 & 0.38 \\
\hline Health fair & 0.04 & 0.03 & 0.03 & 0.03 & 0.27 & 0.21 & 0.26 & 0.25 \\
\hline Health poor & 0.00 & 0.00 & 0.00 & 0.00 & 0.08 & 0.08 & 0.07 & 0.09 \\
\hline $\mathrm{N}$ & 9,708 & 10,577 & 15,762 & 13,149 & 689 & 676 & 770 & 523 \\
\hline
\end{tabular}

Source: SIPP 1984, 1990, 1996, 2001. 
Differences in education and occupational distributions may explain part of the observed disability-related wage gap. On average nondisabled men have higher educational attainments than men with disabilities. Nondisabled have less labor market experience, however, because the prevalence of disability tends to increase with age. ${ }^{8}$ Interestingly, the disabled/nondisabled gap in potential experience of employed men decreased by about three years over the study period. ${ }^{9}$ Turning to the differences in distributions across occupation and industry, men with disabilities are under-represented relative to nondisabled men in high-paying jobs such as managerial/professional occupations and over-represented in manual jobs. We do not find notable differences between the groups in the employment shares by industry.

Men with disabilities are more likely to be employed part-time than nondisabled men and this difference widened over the study period. Both groups show increases in the proportion of part-time workers in the period after enactment of the ADA. However, rates of part-time employment increased much more dramatically among the disabled groups, so the absolute differential in employment rates increased from 3.5 to 20 percentage points between 1984 and $2001 .^{10}$

In line with expectations, a higher proportion of men with disabilities self-report their health status as fair or poor relative to nondisabled men. Finally, while the average amount of nonwage income for nondisabled men decreased somewhat across the study period, average unearned income for men with disabilities increased from $\$ 847$ in 1984 to $\$ 976$ per month in 2001 (Table 1). ${ }^{11}$ We conjecture that a higher proportion of recipients of disability benefits in the period after the ADA could be a possible reason for the increase in nonwage income within the disabled group.

\footnotetext{
${ }^{8}$ The measurement error associated with using potential experience as a proxy for labor market experience is probably greater for the disabled group because they are more likely to have absences from the labor market due to their poor health conditions.

${ }^{9}$ The decrease in the disabled/nondisabled age gap primarily contributes to the change in the potential experience gap. The mean age of the nondisabled group increased between 1984 and 2001 (from 35.3 to 37.8 ) whereas the mean age of the disabled group declined slightly (from 45 to 44.5 ). The gap in educational attainment also narrowed which partly contributes to closing the potential experience gap (because potential experience is computed after formal schooling is complete).

${ }^{10}$ Over the same study period, Hotchkiss (2004) also reports a relative increase in part-time employment among the disabled and that the increase is primarily voluntary. She offers two explanations for the change: (1) Part-time jobs may have become more attractive to disabled workers as employers accommodated their disabilities by allowing disabled workers to work part-time in jobs that would be available only on a full-time basis for non-disabled workers. (2) Policy changes such as the extension of Medicaid and increased disability support allowances from SSI and SSDI may have made part-time jobs more financially viabled for workers with disabilities.

${ }^{11}$ As shown in Table 3, nonwage income is the most critical factor explaining the employment participation decision regardless of disability status. Higher unearned income is expected to increase the reservation wage and this change could explain the increase in unemployment rates within the disabled group.
} 


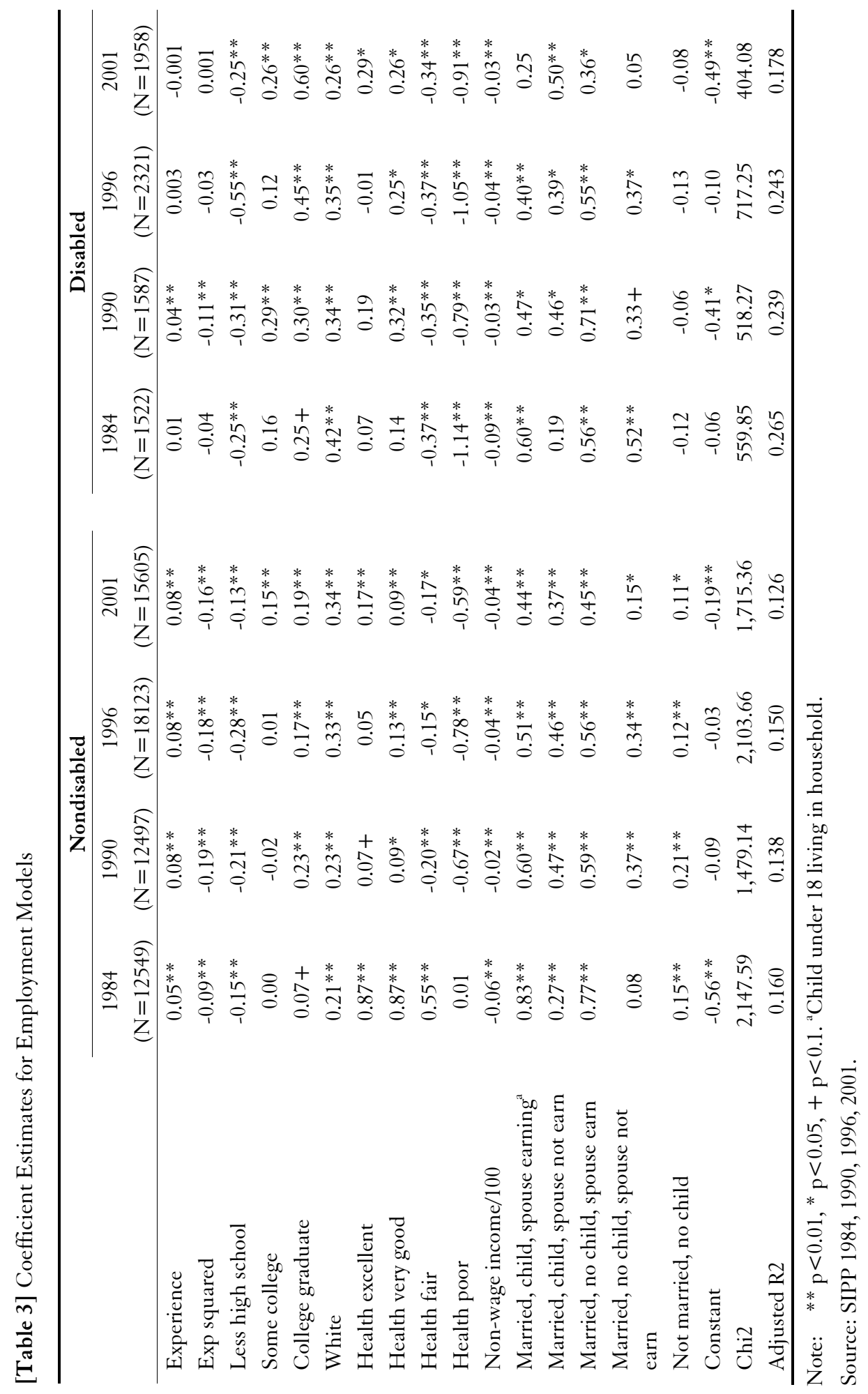




\section{Employment and Wage Equations}

Coefficient estimates for the employment equations are provided in Table 3, and most results are in accord with expectations. For both the disabled and the nondisabled groups, higher educational attainment increases the probability of being employed. The marginal effects of the education variables are, however, stronger for the disabled group, indicating the particular importance of obtaining higher education for men with disabilities. There are also strong and significant effects of work experience with positive signs on the linear terms and negative signs on the quadratic terms, in all cases (except for the disabled group in 2001).

Whites are more likely to be employed than other racial/ethnic groups while married men are more likely to be employed than men with dependents but no spouse (the reference group). Unearned income has pronounced negative effects on labor force participation, consistent with the theory that non-wage income increases reservation wages, regardless of health status. Persons who report better health are more likely to be employed than those in poorer health. ${ }^{12}$

Turning to the coefficient estimates for the wage models, it seems the determinants of wages are similar for men with and without disabilities (Table 4). Potential experience and education have significant positive effects on wages for both disabled and nondisabled men. Although some coefficients are not statistically significant at the traditional levels for the disabled group, the signs of the coefficients are still consistent with predictions. Whites and union members typically earn more, while part-time workers earn less.

Relative to the service occupation (the omitted category), all other occupations except unskilled "laborer" (and sometimes "semi-skilled" laborer) pay higher wages. Individuals in professional and managerial occupations receive the highest earnings, on average. Coefficients of the industry dummies have fairly consistent positive effects, indicting most industries pay higher wages than the omitted group (agriculture, forestry, and fisheries). Although both occupation and industry dummies provide significant explanatory power in most of the wage models, these variables do not have good explanatory power in the wage models for workers with disabilities in 1996 and 2001.

It is also worthwhile to note that self-reported health conditions have pronounced effects on wages for both the disabled and nondisabled groups, although several coefficient estimates are not statistically significant. Workers who self-report poorer health earn lower incomes, but in many cases the coefficient estimates on health status for those are statistically insignificant for men with disabilities.

\footnotetext{
${ }^{12}$ We should be cautious with this interpretation. As many studies have suggested, unemployed individuals may report poor health status to justify not working. Furthermore, responses for health status may not be independent of the labor market effects we want them to explain. For example, it is possible that health status may deteriorate when unemployed.
} 


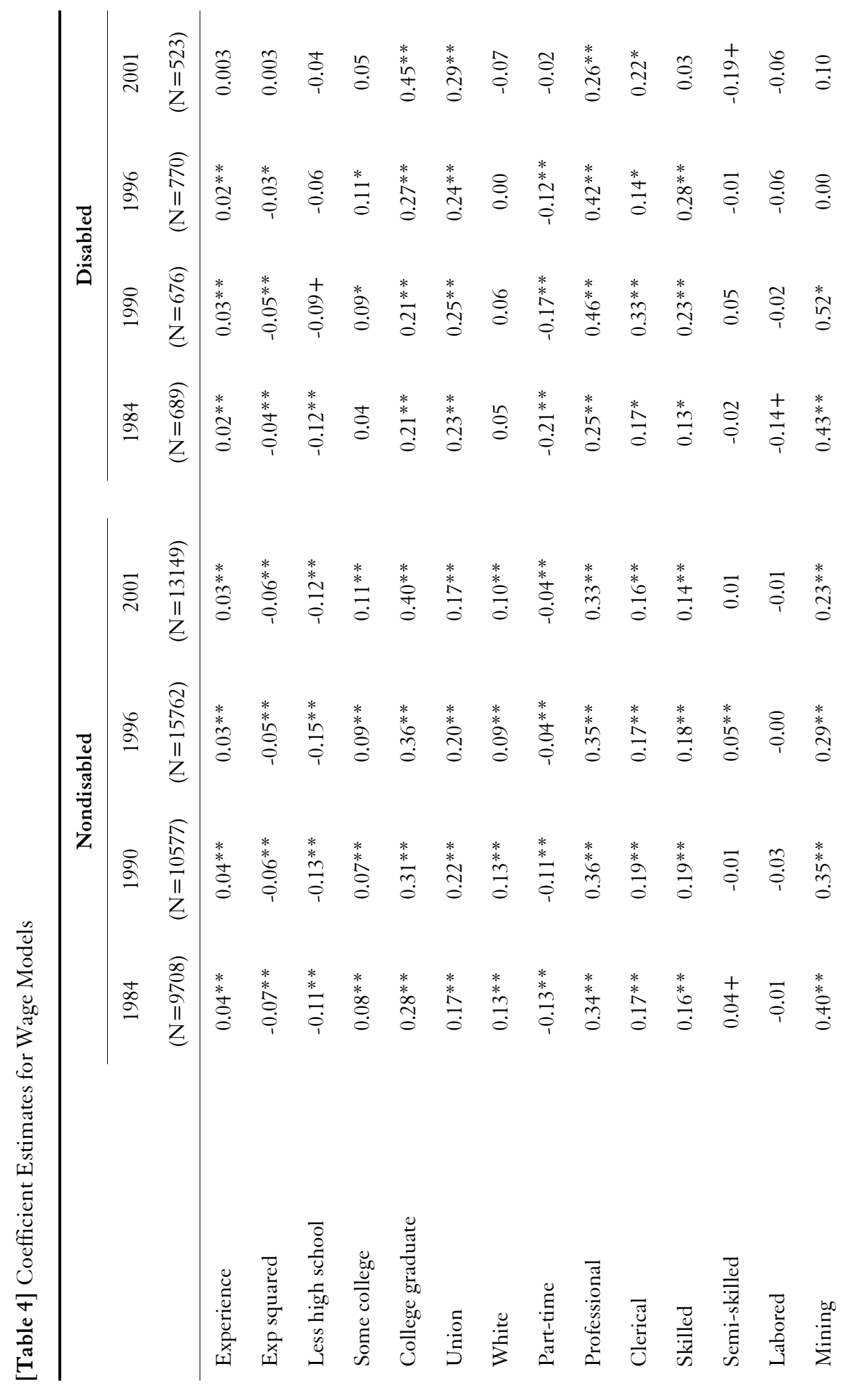




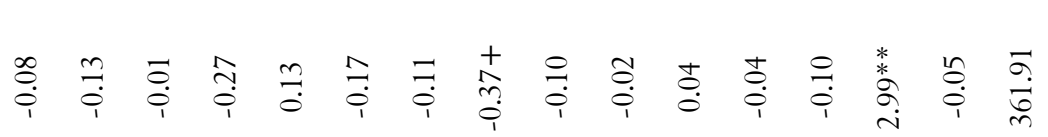

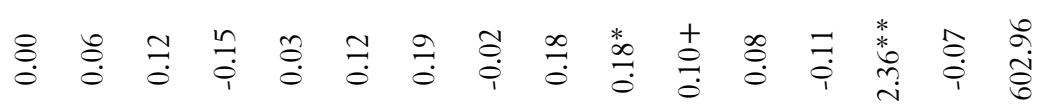

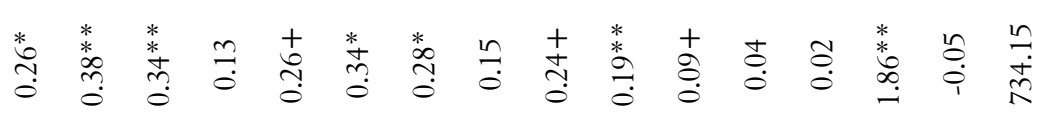

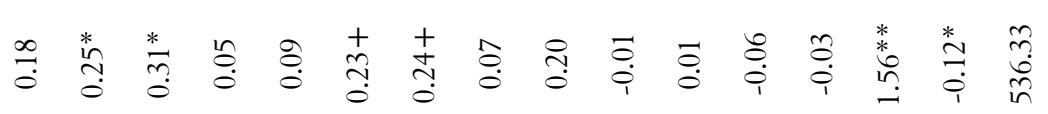

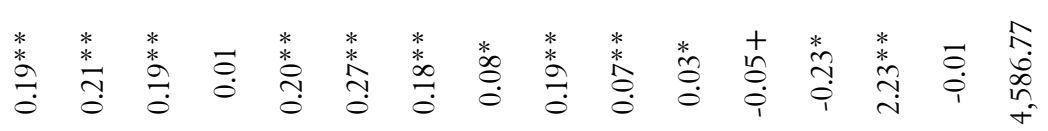

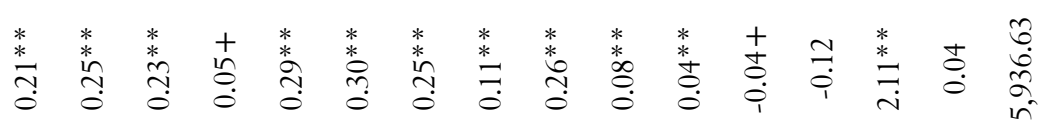

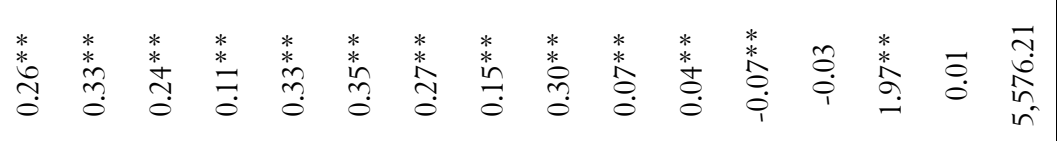

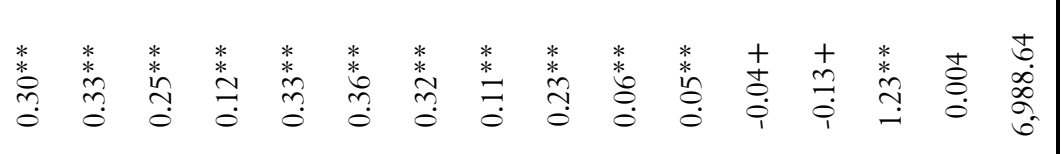

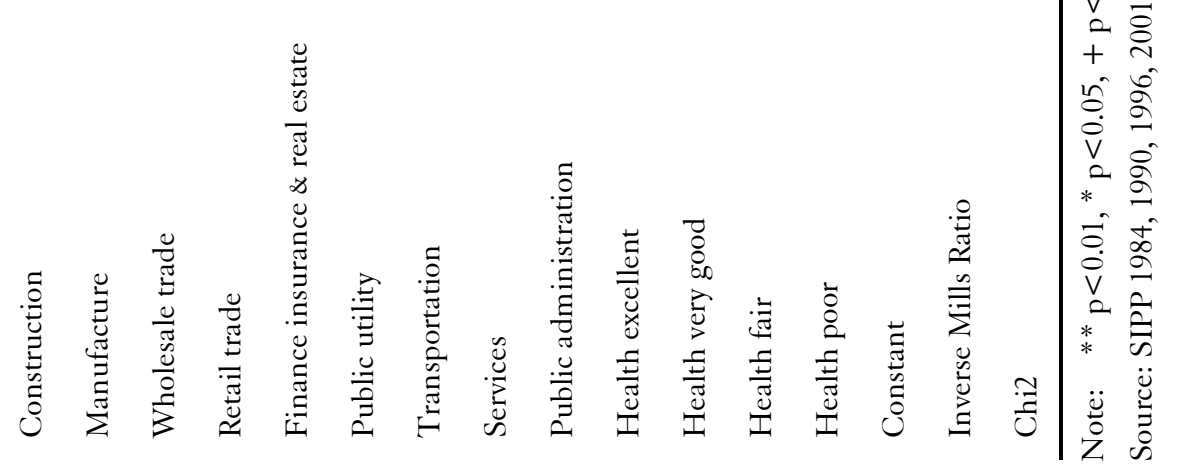


Sample selection into employment does not have a significant effect on earnings for either group. The coefficient estimate for selectivity correction variable is statistically insignificant for both groups in every sample (except the 1984 sample of men with disabilities) Given that most of the coefficients of the selectivity correction terms are statistically insignificant, it is likely that the results are little affected by whether or not a correction is made for sample selectivity.

\section{Decomposition Results of the Differentials in Employment and Earnings}

The main question addressed by this research is to what extent the employment and wage differentials are attributed to unexplained factors (discrimination and residual effects) vs. productivity related characteristics. Table 5 reports decomposition results for disability-related employment and wage differentials. The decompositions of employment differentials (from Equations (3) and (4)) shed light on the increasing gap in employment rates between disabled and nondisabled men over time (from 32.5 percentage points in 1984 to 57.5 percentage points in 2001). We find the relative importance of the two components in explaining the increasing employment differential has changed over time.

[Table 5] Decompositions of Employment and Wage Differentials between Men with and without Disabilities ${ }^{\mathrm{a}}$

\begin{tabular}{lcccc}
\hline & 1984 & 1990 & 1996 & 2001 \\
\hline Employment differential & 0.315 & 0.418 & 0.536 & 0.575 \\
Explained differential & $0.140^{* *}$ & $0.124^{* *}$ & $0.184^{* *}$ & $0.174^{* *}$ \\
& $(44 \%)$ & $(30 \%)$ & $(34 \%)$ & $(30 \%)$ \\
Unexplained differential & $0.175^{* *}$ & $0.294^{* *}$ & $0.352^{* *}$ & $0.401^{* *}$ \\
& $(56 \%)$ & $(70 \%)$ & $(66 \%)$ & $(70 \%)$ \\
\hline Log wage differentials & & & & \\
Explained & 0.115 & 0.189 & 0.220 & 0.176 \\
& $0.030^{* *}$ & $0.063^{* *}$ & $0.099^{* *}$ & $0.121^{* *}$ \\
Unexplained & $(26 \%)$ & $\left(33 \%^{*}\right)$ & $(45 \%)$ & $(69 \%)$ \\
& $0.085^{* *}$ & $0.126^{* *}$ & $0.120^{* *}$ & $0.055^{*}$ \\
Detailed decomposition of the explained component & & $(55 \%)$ & $(31 \%)$ \\
\hline Demographics & $(74 \%)$ & $(67 \%)$ & & \\
Experience & $-0.004^{* *}$ & $0.006^{* *}$ & $0.014^{* *}$ & $0.005^{*}$ \\
Education & $-0.082^{* *}$ & $-0.054^{* *}$ & $-0.049^{* *}$ & $-0.031^{* *}$ \\
Industry & $0.048^{* *}$ & $0.037^{* *}$ & $0.049^{* *}$ & $0.051^{* *}$ \\
Occupation & -0.001 & $0.010^{* *}$ & $0.008^{* *}$ & $0.011^{* *}$ \\
Health & $0.022^{* *}$ & $0.025^{* *}$ & $0.030^{* *}$ & $0.028^{* *}$ \\
Lambda & $0.047^{* *}$ & $0.038^{* *}$ & $0.051^{* *}$ & $0.055^{* *}$ \\
\hline
\end{tabular}

Note: ${ }^{* *} \mathrm{p}<0.01,{ }^{*} \mathrm{p}<0.05 ;{ }^{\mathrm{a}}$ Standard error is computed by bootstrapping (50 replications) for employment decomposition and by the delta method for wage decomposition, respectively.

Source: SIPP 1984, 1990, 1996, 2001. 
Between 1984 and 1990 (the year the ADA was adopted), the unexplained gap in employment rates increased from 17.5 percentage points to more than 29.4 percentage points. This increase in the unexplained component accounts for most of the increase in the employment differential from 1984 to 1990. In relative terms the unexplained portion of the employment differential increased from $55.5 \%$ of the total differential in 1984 to $70.4 \%$ in 1990 .

Even after 1990, the absolute magnitude of the unexplained differential continues to contribute to the widening differential in employment rates between disabled and nondisabled men. In the latter period, however, an increase in the explained part of the employment differential also contributes to the widening gap in employment rates. In this period the relative contribution of the unexplained differential stays at approximately the same level as in 1990 (69.9\% in 2001).

Thus, it appears that between 1984 and the passage of the ADA in 1990 most of the increase in employment differentials between disabled and nondisabled men was attributed to an increase in the unexplained differential (both in absolute and relative terms). After passage of the $\mathrm{ADA}$ the absolute magnitude of the unexplained differential continued to increase but the relative importance of the unexplained differential remained constant. Overall, the findings on employment outcomes are in line with previous studies which find deteriorating employment opportunities for persons with disabilities in the post-ADA period. In contrast to the pre-ADA period, however, the relative importance of the unexplained component remains constant even though the unemployment gap was widening.

In contrast to the results for employment, the raw wage difference between disabled and nondisabled men has not increased dramatically after introduction of the ADA. While the wage gap increased from $\$ 2.78$ in 1984 to $\$ 4.23$ in 1990 , a 52 percent increase, the gap increased only 23 percent over the next six years (to $\$ 5.22$ in 1996) and then declined to a level lower than in 1990 (\$4.12 in 2001).

Table 5 reports results from the wage decompositions which provide insight into the sources of the changes in the wage differential over time. There has been a significant change in wage differentials attributed to between-group differences in productivity-related characteristics and to the wage structure. The unexplained components of the log wage differential has not risen so dramatically, in fact it rose from $7.9 \log$ points in 1984 to $12.6 \log$ points in 1990, fell slightly to $12 \log$ points in 1996, and decreased sharply to $5.5 \mathrm{log}$ points in 2001. If the relative unobserved productivity of employed men with disabilities has not changed over time, it does not appear that the extent of wage discrimination in 2001 is any worse than it was in 1990, the year the ADA was passed.

In 1984 when the overall differential in wages was low at $10.6 \log$ points, the decomposition of the wage shows that $75 \%$ of the differential is attributable to the unexplained differential. By 1990 the wage differential had risen to $18.9 \log$ points in 1990s, and a large proportion of the increase was still attributable to the 
immeasurable factors. By 1996, six years after the ADA was passed, the wage differential had risen to $22 \log$ points, largely due to an increase rise in differences in measurable characteristics between disabled and nondisabled men (from 6.3 to 9.9 $\log$ points). Between 1996 and 2001, the overall wage differential decreased slightly to $17.6 \log$ points, but the explained portion increased again to $12.1 \mathrm{log}$ points. If interpreting the results from the point of relative terms, as shown in Table 5, the discrimination portion has consistently decreased from $74.6 \%$ in 1984 to $31.4 \%$ in 2001.

Table 5 also decomposes the explained component of wage differentials into subcomponents. ${ }^{13}$ While the negative contributions of labor market experience to the explained wage differentials have narrowed, the effects of education do not show a significant change over time. With respect to experience, the average age of disabled men has decreased, and the coefficient estimates of the experience variable have also decreased (Table 4). These two changes both led to a decrease in the part of the explained differential attributed to differences in work experience from -8.7 in 1984 to $-3.1 \log$ points in 2001 .

The results also suggest that differences in occupational distributions and health status play a major role in explaining earnings differences between disabled and nondisabled men. Nondisabled men are more likely to be in higher paying occupations, which explains $2.3 \log$ points of the wage differential between disabled and nondisabled men in 1984, and moderately increases over time. ${ }^{14}$ Nondisabled men also have better health, which explains $4.7 \log$ points of the wage differential in 1984. As shown in Table 5, after a decline in the contribution of health factors in 1990 (to $3.8 \log$ points), the wage differential explained by differences in health status increases to to $5.1 \log$ points in 1996 and $5.5 \log$ points in 2001.

The results show that the gaps between disabled and nondisabled men increased markedly both for the probability of employment and the wage rate between the pre- and post- ADA periods. Compared to nondisabled men, men with disabilities were much less likely to be employed in 2001 than they were in 1984. Disabled workers also experienced declining levels of hourly earnings relative to their

\footnotetext{
13 As shown in Oaxaca and Ransom (1999), the separate contribution of discrete variables to the unexplained portion of the wage decomposition is impossible to identify because the residual term is not invariant with respect to the choice of reference groups, and a similar identification problem applies to continuous variables.

${ }^{14}$ We admit that some variables are endogenously determined by the disability status. For instance, people with disabilities would choose occupation or industry where they can minimize the wage penalty by considering the job demand and the disability types. And this will bias our estimates of the explained and unexplained components. Due to the data limitation, instead of checking the endogeneity issue directly, we conduct the decomposition analyses not including the occupation and industry variables. As expected, the unexplained gap becomes larger when not controlling for those variables, but the general trends of the explained and unexplained gaps remain constant. Complete results are available upon request from the author.
} 
nondisabled counterparts. Based on the decomposition analyses, non-trivial portions of both the employment and wage differentials are attributable to unexplained component of the differentials. Similarly to the findings of prior research (DeLeire 2000, 2001; Acemoglu and Angrist 2001; Beegle and Stock 2003), this study confirms that persons with disabilities experience greater discrimination in employment opportunities than in wages.

\section{Discussion}

From the SIPP questionnaire we can define three distinct types of disabilities: sensory, physical, and activity limitations. If the results in this article are driven by disproportionate increases or decreases in a certain type of disability, our interpretation of the results as connected to the ADA may be less plausible. As displayed in Fig. 1, compared to 1984 and 1990, the disabled sample is composed of a higher proportion of persons with sensory and physical limitations in 1996 and 2001. While these differences in disability composition are apparent across the different surveys, it does not seem that changes in the composition of disability types are systematically related to the magnitude of the explained and unexplained differentials over time.

Although the definition of disability used in this article has the advantage of asking for direct information on work ability and is extensively used in labor market analyses (Kidd et al., 2000; Acemoglu and Angrist, 2001; DeLeire, 2000), it is subjective and may be subject to social and economic incentives to misreport disability status (Bound, 1991; Currie, 1999). Alternatively, We use self-reported functional limitations to define the disabled group in this study and conduct empirical analyses. While some changes are found, compared to the present findings, the empirical evidence still shows similar associations between the ADA and the measures of the explained and unexplained components.

If important determinants of employment participation or wages are omitted from the models, the residual captures these effects and our estimates of discrimination effects may be biased. For instance, although we attempted to control for the impact of poor health on worker productivity by including selfassessed health status in our analyses, it is difficult to adequately control for the impact of disability upon productivity. In this case, the results that we have described might be interpreted as upper bounds within which the true measures of employment and wage discrimination are likely to fall.

We also need to be careful in associating changes in explained and unexplained components of the differentials with the ADA as the study period spans longer. As the observation period increases the possibility of changes in confounding factors 
increases as well. Indeed, many other policy reforms, including the expansion of Medicaid and SCHIP programs occurred over the same period, which are likely to have had confounding effects on employment. Other changes, such as transitions in the structure of the labor market or level of technology, unrelated to the ADA, may or may not affect the results reported in this article by changing the impact of a disability on labor market performance. ${ }^{15}$ While further analysis of different types of disabilities would provide us with a better understanding of the association between the ADA and labor market outcomes among people with disabilities, it is beyond the scope of this article. We instead admit that limitation should be acknowledged when interpreting the empirical evidence in this study.

\section{Concluding Remarks}

We provide estimates of the explained and unexplained (discrimination and residual effects) components of employment and wage differentials between disabled and nondisabled men for a 17 year period spanning introduction of the Americans with Disabilities Act. Using data from the 1984, 1990, 1996, and 2001 panels of the SIPP, we investigate changes in measures of discrimination in the labor market before and after the Act. While observed employment and wage differentials have increased over the study period, the decomposition analyses reveal differences in the trends for wages and employment.

Between 1984 and 1990 (the year in which the ADA was passed), the gap in employment rates between disabled and nondisabled men increased by about 31 percent (from 32.1 to 42 percentage points) and the wage gap nearly doubled (from $\$ 2.78$ to $\$ 4.23)$. For both outcomes, most of the increase in the gap between disabled and nondisabled men was attributable to increases in factors that were not measured in the analysis, that is, the part of the differential potentially attributed to discrimination. Based on the results from the decomposition analyses, we cautiously say that the rise in employment and wage gaps may be attributable to an increase in discrimination against people with disabilities in the years immediately prior to the ADA.

After passage of the ADA the disabled/nondisabled employment differential increased significantly (from 42 to 57.6 percentage points). Both measured and unmeasured factors contributed to the increase in employment differentials, but discrimination measured in relative terms remained constant at around $70 \%$ of the overall employment gap.

In contrast, the disabled-nondisabled wage differential in 2001 was roughly

${ }^{15}$ For instance, since 1980 s in the US, returns to education have been considerably increased, resulting in the dramatic increase in the wage inequality. 
similar to the differential observed prior to passage of the ADA. After 1990 the wage gap first increased (to $\$ 5.22$ in 1996) and then decreased (to $\$ 4.12$ in 2001). The changes in wage differentials were primarily associated with an increase (from 1990-1996) then decrease (from 1996-2001) in the explained part of the wage differential.

The ADA appears to have been associated with a decrease in unexplained wage differentials both in absolute and relative terms, a part of which might be associated with economic discrimination. The empirical results do not show a similar trend for the unexplained part of the employment differential, which increased in absolute terms, and remained constant in relaitve terms in the post-ADA period. Overall, it seems discrimination on entry to employment is more important than wage discrimination for persons with disabilities and the ADA was less effective in reducing employment discrimination than wage discrimination.

An obvious and interesting extension of this research would be to examine how the results differ for different types of disabilities. It would be interesting to know, for example, if the ADA was more successful in opening up employment opportunities and reducing wage discrimination for persons with physical rather than mental disorders. Another interesting extension would be to apply these sophisticated econometric tools to measure labor market discrimination against persons with disabilities using Korean data, which have rarely been used for this type of analysis. We leave these avenues for future research. 


\section{References}

Acemoglu, Daron and Joshua D. Angrist (2001), "Consequences of Employment Protection? The Case of the Americans with Disabilities Act," Journal of Political Economy, 109(5), 915-957.

Baldwin, Marjorie and William G. Johnson (1994), "Labor Market Discrimination Against Men with Disabilities," Journal of Human Resources, 29(1), 1-29.

(2000), "Labor Market Discrimination Against Men with Disabilities in the Year of the ADA," Southern Economic Journal, 66(3), 548566.

Beegle, Kathleen and Wendy A. Stock (2003), "The Labor Market Effects of Disability Discrimination Laws," Journal of Human Resources, 38(4), 806-859.

Bound, John (1991), "Self-reported Versus Objective Measures of Health in Retirement Models," Journal of Human Resources, 26(1), 106-138.

Currie, Janet (1999), "Health, Health Insurance, and the Labor Market," Handbook of Labor Economics, Volume 3, Edited by O. Ashenfelter and D. Card.

DeLeire, Thomas (2000), "The Wage and Employment Effects of the Americans with Disabilities Act," Journal of Human Resources, 35(4), 693-715.

(2001), "Changes in Wage Discrimination Against People with Disabilities: 1984-93," Journal of Human Resources, 36(1), 144-158.

Even, William E. and David A. MacPherson (1990), "Plant Size and The Decline of Unionism,” Economics Letters, 32, 393-398.

Hotchkiss, Julie L. (2004), “Growing Part-Time Employment Among Disabled Workers: Marginalization or Opportunity?” Federal Reserve Bank of Atlanta, Economic Review, (Q3 2004), 24-40.

Johnson, William G. and James Lambrinos (1985), "Wage Discrimination Against Handicapped Men and Women," Journal of Human Resources, 20(2), 264-77.

Jones, Melanie K. (2008), "Disability and the Labour Market: A Review of the Empirical Evidence," Journal of Economic Studies, 35(5), 405-424.

Jones, Melanie K., Paul L. Latreille, and Peter J. Sloane (2006), "Disability, Gender, and the British Labour Market," Oxford Economic Paper, 58, 407-449.

Kidd, Michael P., Peter J. Sloane, and Ivan Ferko (2000), "Disability and the Labour Market: An Analysis of British Males," Journal of Health Economics, 19, 961-981.

Moon, Sangho and Jaeun Shin (2006): "The Effect of the Americans with Disabilities Act on Economic Well-being of Men with Disabilities," Health Policy, 76, 266-276.

Neuman, Shoshana and Ronald L. Oaxaca (2004), "Wage Decomposition with SelectivityCorrected Wage Equations: A Methodological Note," Journal of Economic Inequality, 2(1), 3-10.

Oaxaca, Ronald L. (1973), "Male-Female Wage Differentials in Urban Labor Markets," International Economic Review, 9, 693-709.

Oaxaca, Ronald L. and Michael Ransom (1999), "Identification in Detailed Wage Decompositions," Review of Economics and Statistics, 81(1), 154-157. 
Schumacher, Edward J. and Marjorie L. Baldwin (2000), "The Americans with Disabilities Act and the Labor Market Experience of Workers with Disabilities: Evidence from the SIPP,” Working Paper 0013, East Carolina University, Department of Economics. 